\title{
Analisis Neutronik Pada Gas Cooled Fast Reactor dengan Variasi Strategi Shuffling Bahan Bakar Arah Radial
}

\author{
Muthia Annisa Putri*, Dian Fitriyani, Feriska Handayani Irka \\ Jurusan Fisika FMIPA, Universitas Andalas, Padang \\ *muthiaannisa212@ymail.com
}

\begin{abstract}
ABSTRAK
Analisis neutronik pada Gas Cooled Fast Reactor (GCFR) dengan variasi strategi shuffling bahan bakar telah dilakukan dengan pengaturan awal daya reaktor 550 MWTh dan umur 100 tahun menggunakan input bahan bakar uranium alam tanpa pengayaan. Bahan bakar pada pada teras reaktor dibagi atas 10 region, dengan label region 1 hingga region 10. Setiap region bahan bakar mengalami perbedaan lama proses burnup dan perbedaan densitas nuklida. Variasi strategi shuffling dilakukan dengan cara menyusun masing-masing region bahan bakar secara acak dari region 1 hingga 10. Pada penelitian ini dirancang 4 macam variasi strategi shuffling bahan bakar arah radial. Shuffling bahan bakar dilakukan sekali dalam 10 tahun bersamaan dengan periode refueling. Perhitungan dilakukan dengan metode komputasi menggunakan kode SRAC dengan input data nuklir dari JENDL-32 Library dengan model teras silinder 2D R-Z. Hasil analisis menunjukkan bahwa berdasarakan nilai faktor multiplikasi efektif, variasi strategi shuffling memenuhi kriteria desain reaktor. Strategi shuffling dengan pengaturan region bahan bakar berdensitas fisil tertinggi yang didekatkan dengan region bahan bakar berdensitas fisil rendah menghasilkan densitas ${ }^{239} \mathrm{Pu}$ yang tinggi.

Kata kunci: analisis neutronik, GCFR, SRAC, strategi suffling
\end{abstract}

\section{ABSTRACT}

Neutronic analysis on Gas Cooled Fast Reactor (GCFR) with radial shuffling strategy has been conducted. Neutronic analysis using initial setting 550 MWTh output power, 100 years reactor operation and using natural uranium without enrichment as fuel. The core reactor subdevided into 10 region. Each region are diverification on burnup periode and density. Variation of radial shuffling strategy arranged the region not in sequently from region 1 to region 10. This research designed 4 radial shuffling strategy. Fuel shuffling do every 10 years burnup periode simultaneously refueling periode. Calculation used computation method with SRAC JENDL-32 Library code, with cylindrical $2 D R-Z$ core model. The result show that, base on $k_{\text {eff }}$ value the radial shuffling strategy has fullfilled reactor design criteria. Radial shuffling strategy placing the region with highest fisil contents with the lowest fisil contents produce highest ${ }^{239} \mathrm{Pu}$ densitiy.

Keywords: neutronic analysis, GCFR, SRAC, shuffling strategy

\section{PENDAHULUAN}

Energi nuklir merupakan sebuah teknologi unggul dengan memanfaatkan bahan bakar dengan jumlah yang sedikit dan menghasilkan energi lebih besar yang menjadi harapan baru energi masa depan. Energi nuklir yang dimanfaatkan berasal dari reaksi fisi yang melepaskan sekitar $200 \mathrm{MeV}$ energi. Pemanfaatan reaksi nuklir sebagai sumber energi telah dilakukan sejak Perang Dunia II untuk pengoperasian kapal selam. Pada tahun 1957 energi nuklir digunakan sebagai pembangkit listrik di Chicago. Perkembangan reaktor nuklir sebagai PLTN telah memasuki Generasi IV. Beberapa aspek yang ditingkatkan pada Reaktor Generasi IV seperti kepastian ketersediaan bahan bakar dalam jangka waktu yang panjang, peningkatan efisiensi biaya pembangkit listrik, dan peningkatan aspek keselamatan.

GCFR (Gas Cooled fast Reactor) merupakan salah satu jenis reaktor pembangkit listrik yang dikembangkan pada Generasi IV. GCFR menggunakan helium sebagai pendingin dimana helium dapat beroperasi pada suhu tinggi yang mencapai $850^{\circ} \mathrm{C}$. Selain itu GCFR juga memiliki kemampuan untuk memproses limbah pembuangan nuklir dari hasil bahan bakar bekas tanpa biaya tambahan dengan menggunakannya sebagai bahan bakar Rancangan GCFR memiliki sistem sirkulasi dari Decay Heat Removal (DHR) yang bertujuan menjaga ketahanan suhu reaktor. GCFR juga dapat menggunakan uranium alam tanpa pengkayaan sebagai bahan bakar (GIF, 2017).

Uranium alam memiliki kandungan $0,7 \%$ nuklida bersifat fisil yaitu ${ }^{235} \mathrm{U}$ dan $99,3 \%$ nuklida bersifat fertil yaitu ${ }^{238} \mathrm{U}$. Nuklida fisil merupakan nuklida yang mudah berfisi pada 
semua rentangenergi neutron, sedangkan nuklida fertil mempunyai penampang lintang reaksi yang tinggi hanya pada neutron energi tinggi. Nuklida fertil dapat diubah menjadi nuklida fisil dengan menyerap neutron terlebih dahulu. Strategi khusus diperlukan agar dapat menggunakan uranium alam sebagai bahan bakar, diperlukan strategi khusus dalam pembakaran (burnup) salah satunya adalah strategi shuffling bahan bakar arah radial. Strategi shuffling bahan bakar arah radial merupakan pengembangan dari strategi burnup yaitu CANDLE (Constant Axial Shape of Neutron Flux Nuclide Densities and Power Shape During Life of Energy Producing Reactor).

Rida (2007) melakukan studi desain Pb-Bi Cooled Fast Reactor dengan strategi shuffling arah radial dengan periode refueling 15 tahun menyimpulkan bahwa reaktor yang dirancang dapat beroperasi selama 90 tahun. Irka dkk (2015) meneliti mengenai analisis burnup pada reaktor cepat berpendingin gas menggunakan bahan bakar uranium alam dengan strategi shuffling bahan bakar arah radial. Hasil penelitian menunjukkan bahwa modifikasi burnup bahan bakar dengan strategi shuffling arah radial memungkinkan reaktor beroperasi menggunakan uranium alam tanpa pengayaan dengan mendapatkan nilai faktor multiplikasi efektif $\left(k_{\text {eff }}\right)$ lebih dari 1 sehingga reaktor berada dalam keadaaan kritis dan dapat dioperasikan.

Perbedaan strategi shuffling bahan bakar yang digunakan dapat mengubah keadaan neutronik pada teras reaktor. Keadaan neutronik pada teras reaktor GCFR dilihat berdasarkan analisis neutronik. Oleh karena itu perlu dilakukan analisis neutronik pada GCFR menggunakan strategi shuffling bahan bakar arah radial. Parameter neutronik yang ditinjau yaitu nilai faktor multiplikasi efektif dan densitas ${ }^{235} \mathrm{U},{ }^{238} \mathrm{U}$, dan ${ }^{239} \mathrm{Pu}$.

\section{METODE}

Analisis neutronik dilakukan berdasarkan perhitungan dengan metode komputasi menggunakan kode SRAC yang dikembangkan oleh JAERI (Japan Atomic Energy Research Institute). Spesifikasi desain reaktor yang digunakan dapat dilihat pada Tabel 1.

Tabel 1 Spesifikasi umum desain reaktor

\begin{tabular}{ll}
\hline \multicolumn{1}{c}{ Parameter } & \multicolumn{1}{c}{ Deskripsi } \\
\hline Daya & 550 Mwth \\
Tipe pin sel & Cylindercell \\
Geometri teras & 2-D cylinder \\
Jumlah region bervolume sama dalam arah radial & 10 region \\
Periode refueling & 10 tahun \\
Bahan bakar $($ fuel $)$ & $\mathrm{UN}-\mathrm{PuN}$ \\
Struktur $($ cladding) & $\mathrm{SS} 316$ \\
Diameter pin/pitch & $1,4 \mathrm{~cm}$ \\
Tinggi teras aktif & $3,5 \mathrm{~m}$ \\
Diameter teras aktif & $2,4 \mathrm{~m}$ \\
Lebar reflector & $50 \mathrm{~cm}$ \\
\hline
\end{tabular}

Desain teras yang digunakan dalam penelitian ini bertipe silinder 2-D karena ditinjau dari faktor kebocoran neutron (neutron leakage) dan aliran coolant, maka geometri silinder merupakan geometri yang memberikan kinerja yang optimal. Secara umum teras dibagi menjadi 11 region arah radial dan 2 region arah axial. 10 region pertama merupakan bahan bakar dan yang ke sebelas merupakan reflektor. Pada pembagian arah aksial, region pertama merupakan untuk bakar dan yang kedua untuk reflektor. Geometri sel bahan bakar yang digunakan berbentuk silinder yang terdiri dari 3 region yaitu bahan bakar, cladding (struktur), dan coolant (pendingin).

\subsection{Strategi shuffling Arah Radial}

Variasi strategi shuffling dilakukan dengan mengubah urutan susunan region bahan bakar dengan periode refueling selama 10 tahun. Region bahan bahan bakar dibagi kedalam 10 region. Region 1 merupakan bahan bakar berupa uranium alam yang diposisikan pada pusat 
region, region 2 merupakan bahan bakar yang telah melalui 10 tahun periode burnup begitu seterusnya hingga region 10 yang melalui periode burnup selama 90 tahun. Saat periode refueling, region 1 dipindahkan ke region 2, region 2 dipindahkan ke region 3 begitu seterusnya hingga region 9 dipindahkan ke region 10. Skema simulasi strategi shuffling dapat dilihat pada Gambar 1.

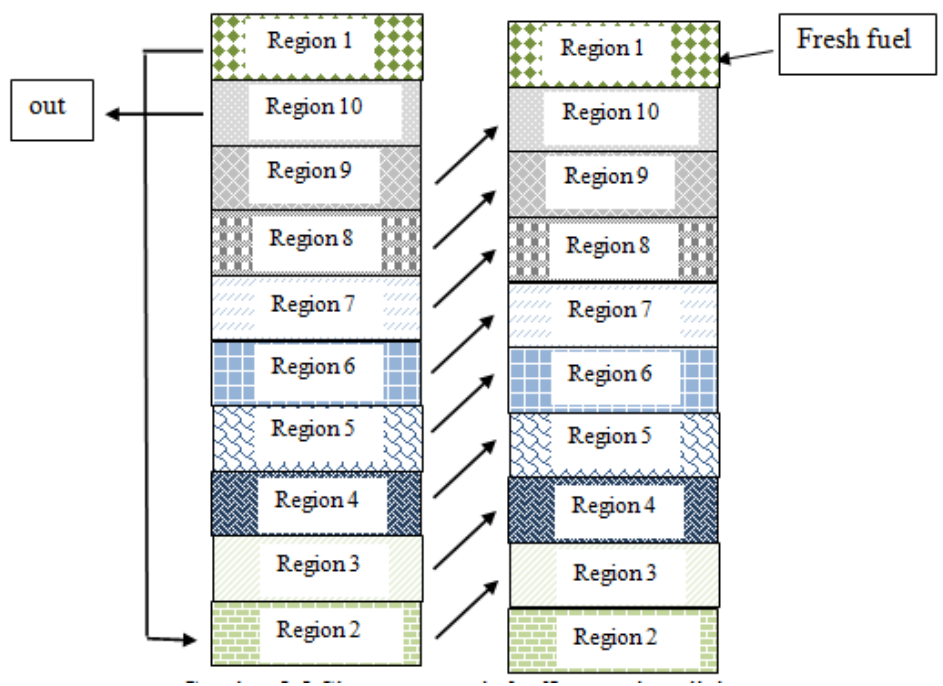

Gambar 1 Skema strategi shuffling arah radial (Sumber: Irka dan Su'ud, 2015)

Variasi strategi shuffling dilakukan dengan mengubah posisi susunan region bahan bakar secara acak. Strategi shuffling bahan bakar arah radial yang digunakan pada penelitian ini dapat dilihat pada Gambar 2.

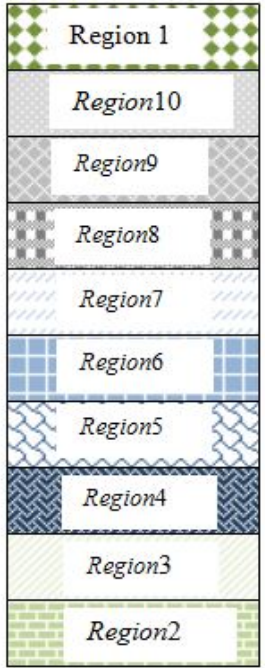

(a)

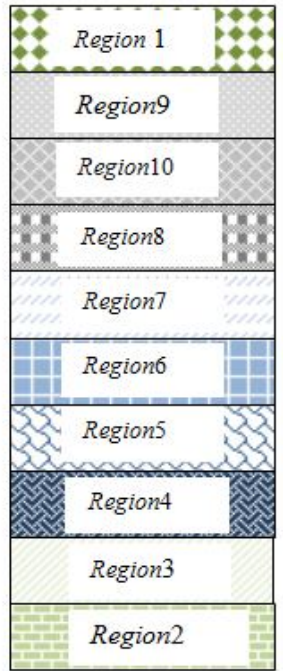

(b)

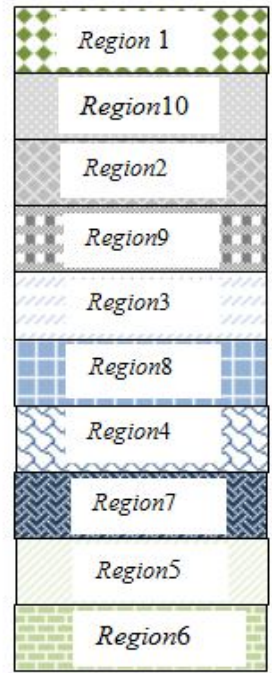

(c)

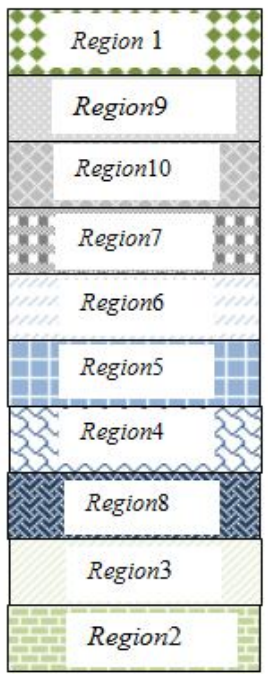

(d)

Gambar 2 Variasi strategi shuffling (a) variasi 1, (b) variasi 2, (c) variasi 3, (d) variasi 4

\subsection{Prosedur Perhitungan SRAC}

Pengolahan data pada penelitian ini menggunakan kode komputasi SRAC. Data yang digunakan adalah data nuklida dari JENDL-3.2, SRAC melakukan perhitungan dan menghasilkan data penampang lintang makroskopik dan mikroskopik dari masing-masing material teras reaktor. Diagram alir untuk perhitungan parameter neutronik menggunakan SRAC dapat dilihat pada Gambar 3. 


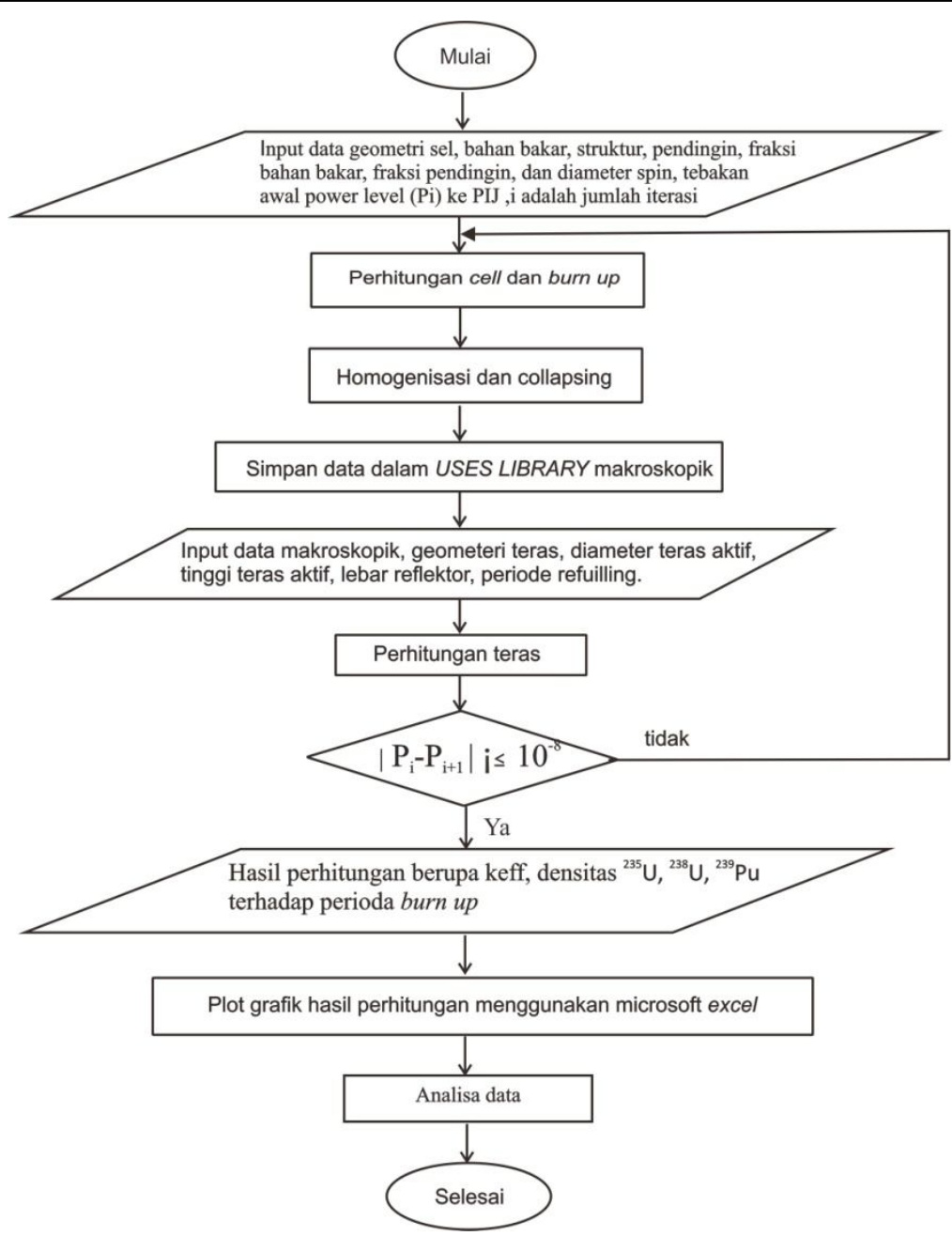

Gambar 3 Diagram alir perhitungan neutronik menggunakan SRAC.

\section{HASIL DAN DISKUSI}

\subsection{Faktor Multiplikasi Efektif $\left(\mathbf{k}_{\text {eff }}\right)$}

Nilai faktor multiplikasi efektif merupakan nilai yang menggambarkan kekritisan reaktor. Reaktor berada dalam keadaan kritis dengan nilai $\mathrm{k}_{\text {eff }}=1$. Nilai $\mathrm{k}_{\text {eff }}$ berdasarkan hasil perhitungan ditunjukkan pada Gambar 4.

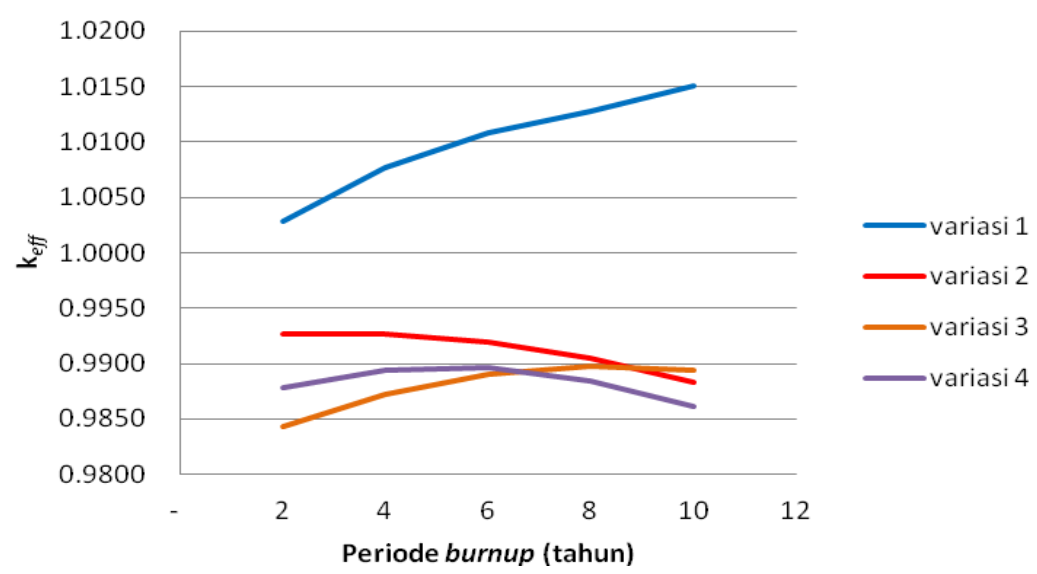

Gambar 4 Hubungan $\mathrm{k}_{\text {eff }}$ terhadap periode burnup pada 4 variasi strategi shuffling bahan bakar arah radial 
Nilai faktor multiplikasi memiliki rentang nilai reactivity swing sebesar $\pm 0,05$. Nilai faktor mulptiplikasi yang baik untuk desain reaktor yaitu dengan nilai faktor multiplikasi efektif pada awal operasi reaktor yaitu berada dalam keadaan kritis atau superkritis (Duderstadt dan Hamilton, 1976).

Keempat variasi yang digunakan menunjukkan reaktor berada dalam keadaan kritis. Dengan menyisipkan region dengan periode burnup yang lebih lama dengan periode burnup yang lebih singkat akan mengurangi neutron yang terdapat pada teras reaktor karena reaksi serapan neutron oleh nuklida yang bersifat fertil. Perbedaan susunan salah satu region pada variasi 2 dan variasi 4 menghasilkan nilai $\mathrm{k}_{\text {eff }}$ yang berbeda, namun dengan selisih penurunan setiap periode burnup sama. Nilai faktor multiplikasi pada variasi 3 cendrung naik selama periode burnup. Hal ini menunjukkan bahwa dengan menempatkan bahan bakar dengan densitas bahan fertil yang lebih besar dengan densitas bahan bakar fisil yang lebih besar dapat meningkatkan jumlah neutron pada teras reaktor.

\subsection{Densitas nuklida ${ }^{235} \mathrm{U},{ }^{238} \mathrm{U},{ }^{239} \mathrm{Pu}$}

${ }^{235} \mathrm{U}$ merupakan nuklida fisil yang terdapat pada uranium alam. ${ }^{235} \mathrm{U}$ bereaksi dengan neutron termal pada teras reaktor yang menghasilkan neutron cepat. Selama reaktor beroperasi ${ }^{235} \mathrm{U}$ menurun karena bereaksi fisi. Hasil reaksi fisi ${ }^{235} \mathrm{U}$ akan menghasilkan neutron baru yang akan bereaksi dengan ${ }^{238} \mathrm{U}$. Densitas ${ }^{235} \mathrm{U}$ variasi 1 menurun lebih konstan dibandingkan dengan variasi lainnya. Penurunan densitas ${ }^{235} \mathrm{U}$ variasi 2 dan variasi 3 lebih besar dibandingkan dengan variasi lainnya. Perbedaan penyusunan region pada variasi 4 terhadap variasi 2 menyebabkan probabilitas reaksi fisi ${ }^{235} \mathrm{U}$ lebih rendah. Grafik hubungan densitas ${ }^{235} \mathrm{U}$ terhadap periode burnup dapat dilihat pada Gambar 5.

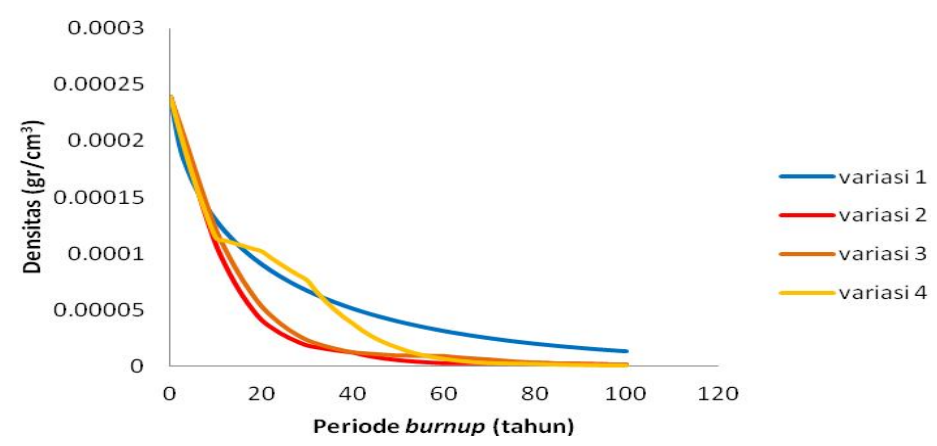

Gambar 5 Hubungan densitas ${ }^{235} \mathrm{U}$ terhadap periode burnup pada strategi shuffling bahan bakar arah radial.

${ }^{238} \mathrm{U}$ pada teras reaktor ditembaka dengan neutron cepat sehingga dapat menghasilkan nuklida baru yang bersifat fisil yaitu ${ }^{239} \mathrm{Pu}$. Grafik hubungan densitas ${ }^{238} \mathrm{U}$ dan ${ }^{239} \mathrm{Pu}$ terhadap periode burnup dapat dilihat pada Gambar 6 dan Gambar 7.

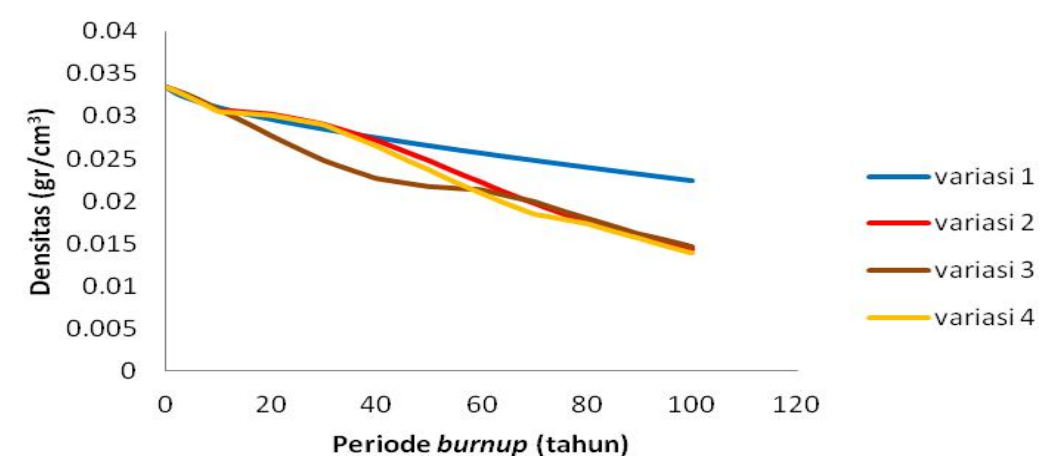

Gambar 6 Hubungan densitas ${ }^{238} \mathrm{U}$ terhadap periode burnup pada strategi shuffling bahan bakar arah radial. 


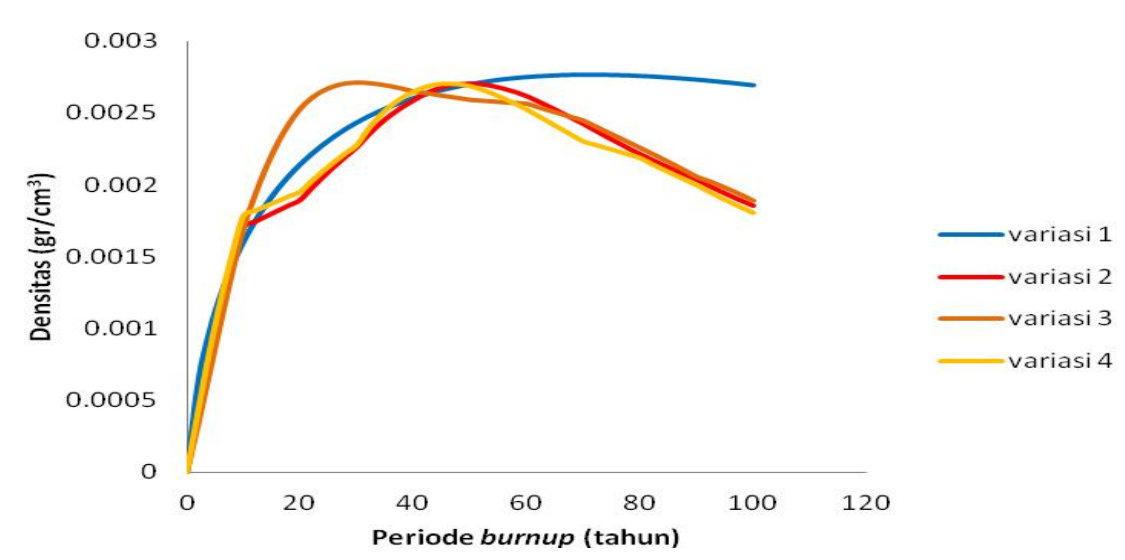

Gambar 7 Hubungan densitas ${ }^{239} \mathrm{Pu}$ terhadap periode burnup pada strategi shuffling bahan bakar arah radial.

Nilai densitas ${ }^{238} \mathrm{U}$ pada variasi 2 dan variasi 4 memiliki nilai yang hampir sama. Densitas ${ }^{238} \mathrm{U}$ pada variasi 4 lebih kecil dibandingkan dengan variasi 2 . Keadaan ini menjadikan densitas ${ }^{239} \mathrm{Pu}$ pada variasi 4 lebih tinggi dibandingkan dengan variasi 2 . Melalui penempatan posisi region 8 yang merupakan bahan bakar dengan periode burnup yang lebih lama diantara region 4 dan region 5 dapat meningkatkan densitas ${ }^{239} \mathrm{Pu}$ pada teras reaktor.

Penurunan nilai densitas ${ }^{238} \mathrm{U}$ pada variasi 3 lebih besar dari variasi lainnya. Keadaan ini menghasilkan densitas ${ }^{239} \mathrm{Pu}$ yang lebih besar dibandingkan variasi lainnya. Diketahui bahwa variasi 3 merupakan strategi shuffling bahan bakar arah radial dengan menempatkan region berkonsentrasi fisil tinggi didekatkan dengan region konsentrasi fertil yang tinggi. Dalam keadaan ini, variasi 3 merupakan strategi shuffling bahan bakar arah radial yang lebih efektif dibandingkan dengn variasi lainnya.

\section{KESIMPULAN}

Berdasarkan nilai faktor multiplikasi efektif, variasi strategi Shuffling yang digunakan memenuhi kriteria kekritisan reaktor dengan nilai reactivity swing $\pm 0,05$. Variasi Strategi shuffling dapat mempengaruhi keadaan neutronik, densitas, yang dihasilkan selama reaktor beroperasi. Variasi 2 menghasilkan reaksi ${ }^{235} \mathrm{U}$ yang lebih efektif. variasi 3 menghasilkan densitas ${ }^{239} \mathrm{Pu}$ yang lebih besar, keadaan ini menunjukkan desain yang lebih optimal dibandingkan variasi lainnya.

\section{DAFTAR PUSTAKA}

Duderstadt, J.J. dan Hamilton, L.J., 1976, Nuclear Reactor Analysis, John Wiley\&Sons, Inc., New York, hal 74-76.

Irka, F.H., dan Su'ud, Z., Analisis Burnup pada Reaktor Cepat Berpendingin Gas Menggunakan Bahan Bakar Uranium Alam (Jurnal Ilmu Fisika, 2015), Hal 78-86.

Rida, S.N.M., Design Study of Long Life Pb-Bi Cooled Reactors With Natural Uranium as Fuel Cycle Input Using Radial Fuel Shuffling Strategy, Proceedings of International Conference on Advance in Nuclear Science and engineering in conjunction with LKTSN 2007, (Institut Teknologi Bandung, 2007).

Generation IV International Forum (GIF), 2017, The Generation IV Gas Cooled Fast Reactor, https://www.iaea.org/GFR_Staisby, diakses Juli 2017. 